\title{
Detecting the onset of spring: a possible application of phenological models
}

\author{
Mark D. Schwartz \\ Department of Geography, San Francisco State University, San Francisco, California 94132, USA
}

\begin{abstract}
The onset of the spring season is a phenomenon associated with systematic changes in the land surface-atmosphere interface, which will likely be modified by climate change. A measure of this complex feature, or 'spring index', should reflect the variations in both weather events and plant physiology usually identified with mid-latitude spring. In this study, variables representing plant phenology, synoptic weather system frequency, surface temperature-thickness relationship 'breaks' (difference between surface maximum temperature and thickness-derived layer mean temperature), and last freeze date $\left(0^{\circ} \mathrm{C}\right.$ or lower) are compared and examined as components of a comprehensive measure of the onset of spring. Two small networks of stations in the eastern and central United States are used as test data over the period 1961 to 1980 . The phenology-synoptic weather component (P-SW), derived from regression-based models of first leaf emergence, has the strongest relationship with other measures, and can be produced from generally available surface data. This component is proposed as a first approximation of a comprehensive spring index, suitable for analyzing the impact of past and future climate changes on the onset of spring
\end{abstract}

\section{INTRODUCTION}

Any global climate change that alters the interannual variability of weather patterns may have adverse or beneficial impacts on ecosystems and selected human activities. One method of assessing the impact of such fluctuations is to examine climates of the recent past, through historic data (Skaggs \& Baker 1985, Coakley \& McDaniel 1988, Karl \& Riebsame 1989). Another is to use Global Climate Models (GCMs) to produce scenarios of future climate (Rind et al. 1989, Smit et al. 1989, Rosenzweig 1990). The onset of the spring season (generally equivalent to the start of vegetative growth) is an example of a complex phenomenon that might be modified by climate change. It is also relevant to climate modeling at many scales. This is partly because as plants break dormancy, foliage production causes albedo changes and a rapid increase in transpiration (Rosenberg 1974, Kaufmann 1984). These processes may subsequently alter the surface layer sensible versus latent heat exchange, which can in turn affect daily weather variables, such as maximum temperature (Oke 1987, Segal et al. 1989, Schwartz \& Karl 1990). Other features affecting the surface energy balance, such as the latitude of snow cover and synoptic storm tracks (cloud cover and rainfall patterns), also change at this time.
Assessing the effects of climate variations on the onset of spring would be facilitated by a simple method which combines all aspects of the phenomenon. Such a 'spring index' should include components reflecting both the changes in weather events, and plant physiology (phenology) usually identified with mid-latitude spring over synoptic-scale $(1000 \times$ $1000 \mathrm{~km}$ ) regions (Lieth \& Radford 1971, Hopp 1974, Schwartz \& Marotz 1986, 1988). Schwartz \& Marotz (1988) developed models of lilac first leaf, based in part on the passage of key synoptic weather systems, which can serve as an approach to measuring the phenology and synoptic meteorological aspects of spring's onset. Schwartz \& Karl (1990) examined average characteristics of springtime breaks in the surface maximum temperature-thickness relationship, related to lilac first leaf, that address another meteorological component of the winter-spring transition period. The purpose of this study is to analyze (on a yearly basis) and compare the component measure techniques presented in previous works, in order to propose one as a first approximation of a comprehensive spring index. This index can be used in subsequent examinations of the impact of past (historic analog) and future (GCM-generated) climate change on the onset of spring. 


\section{LITERATURE REVIEW}

\section{Index components}

A comprehensive spring index should include components reflecting plant phenology and the various meteorological measures associated with the onset of spring (Schwartz \& Marotz 1988). The phenology component might define (by calendar date) an easily identifiable plant change in terms of the sequence of weather events leading up to its occurrence (Hopkins 1938, Hopp et al. 1969, Lieth \& Radford 1971, Hopp 1974, Schwartz 1985). This could be accomplished by incorporating daily weather data from mid-winter through spring into a predictive model which produces a timetable for plant phenology (Schwartz 1985). One meteorological component of the index would be recognition of annual changes in the occurrence of specific synoptic weather system types (Schwartz \& Marotz 1988). A second weather component might be identification of spring 'breaks' in surface layer meteorological conditions. Examination of daily maximum temperatures and the maximum temperaturethickness relationship (difference between surface maximum temperature and thickness-derived layer mean temperature) appears to be an effective approach for this second component (Schwartz \& Karl 1990). Lastly, inclusion of a weather component such as last freeze date would be advantageous, so as to provide some continuity with previous 'growing season' studies (e.g. Brinkmann 1979, Skaggs \& Baker 1985, Suckling 1986)

\section{Index development}

Spring phenological events, such as first leaf or flower bloom, are well suited as constituents of a spring index since they represent the response of the plant to a particular set of environmental conditions over time (Lieth \& Radford 1971). Numerous methods have been used to develop phenology models for a wide variety of plant species (e.g. Partridge 1947, Brown 1960, Lettau 1965). More recently, crop phenology and yield models have been produced and tested (e.g. Duchon 1986, Andresen et al. 1989, Isard \& Easterling 1989, Rosenzweig 1990). These agricultural models emphasize phenology or yield prediction; their relationships to synoptic systems and springtime 'breaks' have not been determined.

Obviously, all plants do not respond in the same way to a set of environmental conditions. An initial way to mitigate this problem is to carefully select one or a small set of 'indicators'. While these chosen plants will not represent all species in an area, they do provide a standard reference that can be compared among differ- ent climate stations and years (Caprio 1974, Hopp \& Vittum 1977, Santer 1985). An appropriate indicator will have a broad distributional range, relatively good insect and disease resistance, phenological stages that are easy to observe, cold hardiness, resistance to heat and drought, and adaptability to a variety of soil types (Hopp et al. 1969, Hopp 1974). Several United States Department of Agriculture regional phenology projects have used hardy shrub clones with all the above attributes (Syringa chinensis 'Red Rothomagensis' lilac, and the Lonicera tatarica 'Arnold Red' and L. korolkowii 'Zabeli' varieties of honeysuckle).

Schwartz \& Marotz $(1986,1988)$ produced a set of synoptic-scale $(1000 \times 1000 \mathrm{~km})$ regression models for Syringa chinensis (lilac) that combine simple data requirements (daily maximum-minimum temperatures) with reasonably accurate plant phenology predictions over a large region (Fig. 1). The best models were based on identification of specific types of synoptic weather systems in the weeks before the phenological event. Therefore, this modeling approach combines 2 components (phenological and synoptic meteorological) of a comprehensive spring index. The technique may also involve other weather components because the first leaf dates of lilac appear to be connected with a break in meteorological conditions of the surface layer (Schwartz \& Karl 1990).

The specific goals of this paper are then to: (1) develop first leaf models for 2 varieties of honeysuckle (Lonicera tatarica and L. korolkowii) using the lilac modeling methods from Schwartz \& Marotz (1988); (2) develop phenology and synoptic weather (P-SW) components of a spring index based on the Syringa chinensis (lilac) and 2 honeysuckle models; (3) identify annual breaks in spring surface layer conditions as additional meteorological components, using the maximum temperature-thickness relationship after Schwartz \& Karl (1990); (4) compare the components (including last freeze date) and propose one as a first approximation of a comprehensive spring index; and (5) conduct simple tests of the index with 2 small networks of stations.

\section{DATABASE AND PROCEDURES}

\section{Phenology-synoptic weather component}

Development of appropriate phenological models requires a long record of event data for representative species, preferably distributed over a large geographic area. Non-climatic regional influences on the plants' behavior, such as topography, genetic variations, and soil types, must be identified or controlled for as much as possible (Hopp 1974, Dube et al. 1984). United States Department of Agriculture regional phenology 


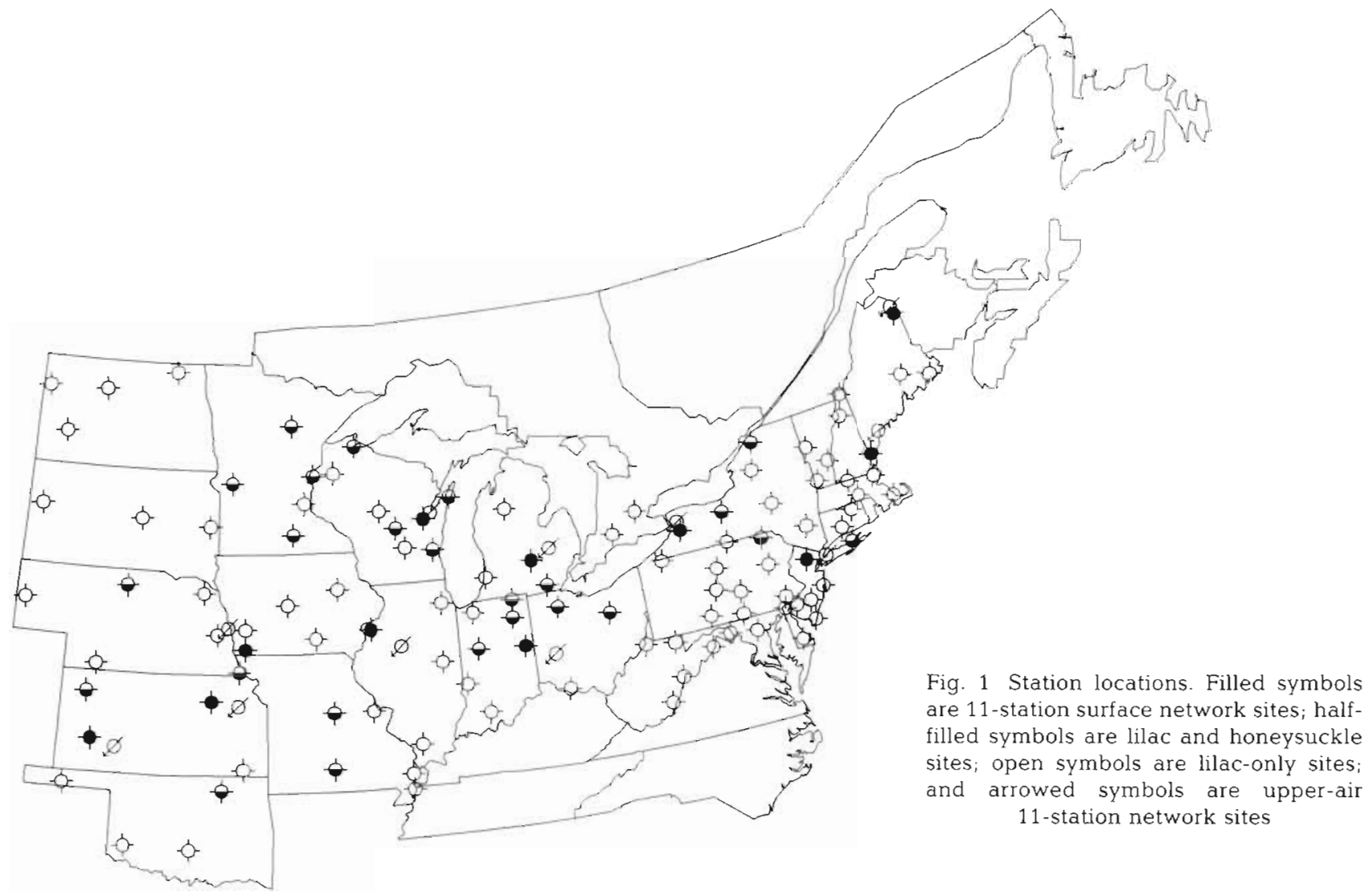

projects have gathered spring phenological data in eastern and central North America since 1961. These projects used a lilac and 2 honeysuckle clone cultivars.

Modeling first leaf is particularly desirable because it represents the start of photosynthetic activity, and may be related to changes in surface albedo and transpiration rates. Schwartz \& Marotz (1988) developed 5 models for the first leaf emergence of Syringa chinensis in a synoptic scale region based on 906 station-years of data from 1961 to 1980 (Fig. 1). All meteorological inputs required for the models were derived from daily maximum and minimum temperatures. The phenological data (day of year counted from January 1) served as the dependent variable in a stepwise multiple regression (model-building) procedure of the form:

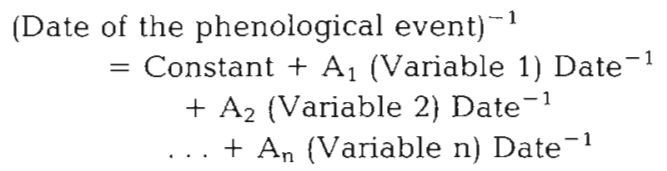

If the standard regression form were used, a model that should produce perfect prediction could have the same independent variable values (e.g. 800 degreedays) associated with different values of the dependent variable (e.g. Days 105 and 115). This would not produce a perfect correlation, even though the model was predicting the event perfectly. Use of the above formulation (Eq. 1) ensures that different dates for the same phenological event, at different stations, do not bias the predictive capabilities of the method (Schwartz 1985).

Phenological data for 2 varieties of honeysuckle (146 station-years, 1971 to 1980 ) are also available at many of the lilac stations (Fig. 1). As part of this study, first leaf emergence models were developed for these 2 plants ('Arnold Red' and 'Zabeli') using the same stepwise multiple regression formulation described above. All models were constructed using a 'progressive' approach, i.e. variables were entered into the regression equations starting from January 1 each year, and entry proceeded until the model indicated that the phenological event had occurred. This approach allows the models to be used for prediction from current weather data as they are recorded because model error is assessed continuously (Schwartz \& Marotz 1988).

For each of the 3 plant types, the best predictive models of first leaf were the 'Synoptic plus Capstones' (SCM+) form. This approach was theoretically based on Fourier and regression analyses of degree-day accumulations in the days before lilac first leaf, conducted by Schwartz \& Marotz (1986, 1988) and Schwartz (1985). The results of these studies showed that first leaf emergence is strongly related to the number of high-sensible-heat-energy synoptic weather 'events' that occur after January 1, and in particular to synoptic events that occur about $1 \mathrm{wk}$ before and at the time of first leaf ('capstones'). 
Four independent variables (significant at the 0.01 confidence level or better) were selected to represent the synoptic event and capstone effects in the SCM+ regression models: (1) number of high energy synoptic events [based on a proxy measure using degree-day accumulations, base $-0.6^{\circ} \mathrm{C}$, higher than $1 \mathrm{SD}$ above the study area mean, shown by Schwartz (1985) to be related to known synoptic weather types], (2) degreeday accumulation for 5 to $7 \mathrm{~d}$ before the present date, (3) degree-day accumulation for 0 to $2 \mathrm{~d}$ before the present date, and (4) station latitude. The first leaf dates (day of year counted from January 1) predicted by each of the $3 \mathrm{SCM}+$ plant models (1 lilac, 2 honeysuckle) were calculated for each station-year and averaged for locations in the original data network, including a smaller group of 59 stations (with full $20 \mathrm{yr}$ temperature records), and then also for an 11 -station network. The latter were used as a test set of values for the P-SW spring index component (Fig. 1).

\section{Atmospheric break-point component}

Schwartz \& Karl (1990) found that a significant break in the relationship between surface maximum temperature and $850 \mathrm{hPa}$ to $700 \mathrm{hPa}$ thickness occurred on average around the time of lilac first leaf. In the weeks after the phenological event, maximum temperatures rose at a much slower rate (relative to thickness values) than the period before. In order to examine this change in more detail, and utilize it as a component of spring index calculations, daily maximum temperatures for a small (11-station) network of surface phenology stations were combined with daily thickness data from the closest upper-air observing locations for the period 1961 to 1980 (Fig. 1). Thicknesses were first converted to layer-mean temperatures by the hypsometric equation, and then differences (surface maximum temperature - layer mean temperature) calculated for each day as a sensitive measure of the maximum temperaturethickness relationship (Schwartz \& Karl 1990).

Both the daily sequence of surface maximum temperatures and differences (described above) for each station-year were then processed by the following objective technique to identify a date of maximum slope decrease: Throughout the spring season (Day 55 to 150 , with January 1 as Day 1 ) for each variable, the least-squares slope for the $30 \mathrm{~d}$ before a given day was calculated, and compared to the $30 \mathrm{~d}$ after that day (Press et al. 1986). For example, on Day 100, the slope of Days 70 to 100 would be compared to that of Days 100 to 130 (numbers from 1 to 30 would be the ' $x$ ' values with variable values as ' $y$ '). The date of the greatest slope decrease (before - after) was identified as the 'break-point' (peak slope decrease) for each station-year. In producing the final break-points, about one-third of these initial objective peaks were adjusted using the following criteria: (1) the middle value in time was selected for small 'plateaus', (2) if 2 peaks of relatively equal size (more than $3 \mathrm{wk}$ apart) occurred in a station-year, the one closest to first leaf was selected, and (3) station-years with more than 2 , or no clear peak (about $5 \%$ ) were designated and removed from further calculations.

\section{Comparison of the components}

As final preparation for analyzing the spring index components, last freeze dates $\left(0^{\circ} \mathrm{C}\right.$ or lower) were computed for each station-year in the 11 -station network over the period 1961 to 1980 . These were then grouped with the previously reported P-SW dates, difference break-point dates, and surface maximum temperature break-point dates. A simple evaluation of variable pair relationships (including the 4 -component average) was performed by calculating Pearson product-moment correlations. As a further comparison, all variables were converted into departure values (yearly value mean value). These departures were then averaged over all stations to produce a mean departure value for each year. In order to filter out short-term variability, each curve was smoothed using a 9 yr (after Skaggs \& Baker 1985), normal-distribution moving-average filter (i.e. for each year 9 values, starting 4 yr before and ending 4 yr after, were weighted with values appropriate to a normal distribution, as described by Holloway 1958). The processed data span from 1965 through 1976, and show only long-term $(9+$ yr) variations. Correlations were also computed between the departure variables and their average.

\section{RESULTS}

The error terms expressing the power of the P-SW component model are shown in Table 1. The adjusted $\mathrm{R}^{2}$ is included for continuity, but this value is not necessarily useful in assessing the predictive ability of regression-based models (Biswas 1980, Wilmott 1982). The mean absolute error [absolute value (predicted observed\}], regarded as a better measure, shows that the P-SW model predicted the average data of first leaf among the 3 plants within about $5.4 \mathrm{~d}$ of its actual occurrence. The intercorrelations of the spring index components (11-station network) are displayed in Table 2. Note that the P-SW variable has the strongest relationship to the 4 -component average.

The smoothed yearly departure values (differences in days from the period means) for each of the compo- 
Table 1 Spring Index Model error statistics. Three-model average for station-years in the original data network with first leaf data available for all plants; $n=134$

\begin{tabular}{|lc|}
\hline \multicolumn{2}{l}{ Statistic } \\
\hline Adjusted R squared & 0.650 \\
Mean absolute error & $5.418^{\mathrm{a}}$ \\
Root-mean-square error & 7.176 \\
Mean phenological date & 97.075 \\
SD of phenological date & 18.979 \\
Mean model date & 98.328 \\
SD of model date & 16.560 \\
& \\
a'This and remaining values are in days, with day of year & \\
dates & \\
\hline
\end{tabular}

Table 2. Component correlations (all significant at the 0.001 confidence level); $\mathrm{n}=187$

\begin{tabular}{|lcccc|}
\hline & Diff. & Max. & Freeze & Aver $^{\circ}$ \\
\hline P-SW & 0.6305 & 0.7735 & 0.5136 & 0.9055 \\
Diff. & & 0.6281 & 0.3130 & 0.8129 \\
Max. & & & 0.2902 & 0.8647 \\
Freeze & & & 0.6205 \\
a Four-component average value & & \\
\hline
\end{tabular}

nents (11-station network) show somewhat different patterns, but generally trend toward negative departures, which would correspond to an earlier onset of spring (Fig. 2). The P-SW component decreases initially, rises to a peak in 1970, and then steadily falls. A similar pattern is displayed for the surface maximum temperature break-point component (Max.), except with higher amplitude. The difference break-point component (Diff.) is also much the same, except that values hold steady in the early 1970's and only decrease at the end of the study period. Last freeze date appears to be out of phase with the other components, reaching an earlier peak, but still showing the prevalent decreasing pattern. The P-SW component (which was essentially the same in phase and magnitude for both the 11- and 59-station networks) had the highest correlation ( $\mathrm{R}=0.9283$, significant at the 0.001 confidence level) with the 4 -components average curve.

\section{DISCUSSION}

The P-SW component appears to have the strongest correlation and temporal pattern relationship with the other components (difference break-point, surface
Fig. 2. Smoothed variable departure values (in days) for 11-station network, 1965 to 1976 . PSW: phenology-synoptic weather component; Diff. difference break-point component; Max.: surface maximum temperature break-point component; Freeze: last $0^{\circ} \mathrm{C}$ or lower freeze date

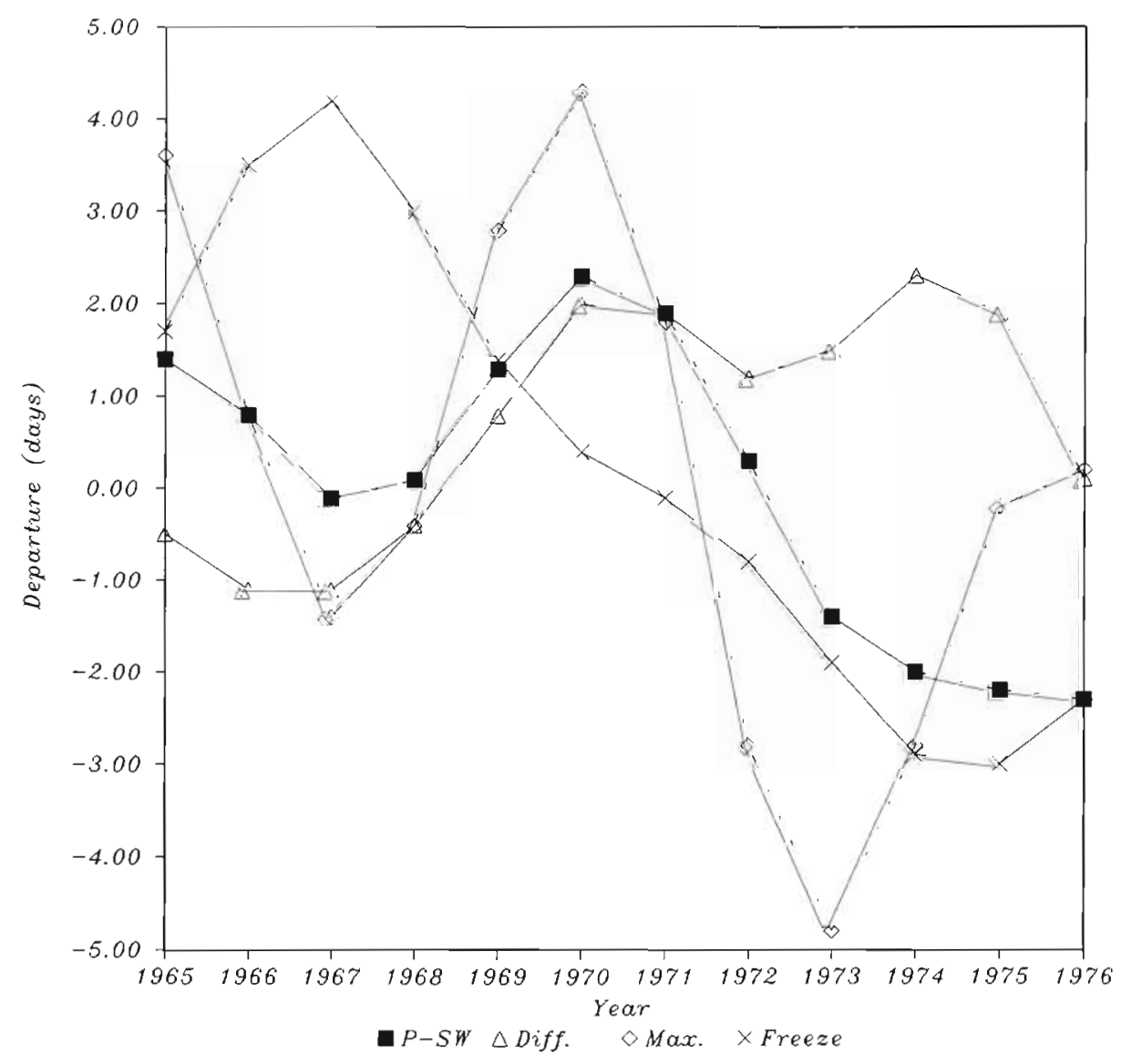


maximum temperature break-point, and last freeze date) over the 1961 to 1980 study period. Further, the PSW model is straightforward and easy to produce from daily surface maximum-minimum data, such as are generally available in the past, or can be produced from GCM output. It seems appropriate then, to propose the P-SW component as a first approximation of a comprehensive spring index, suitable for analyzing changes in the timing of the onset of spring (and associated changes in the land-atmosphere interface).

As an initial study, an analysis of variations in the spring index, incorporating long-term historical weather data, over large geographical areas such as eastern and central North America (Fig. 1) would seem appropriate. Adjacent or other mid-latitude locations might also be examined, as preliminary indications are that the P-SW model can produce accurate predictions in other climatic regions. For such larger studies, the utility of the spring index might be improved by the addition of precipitation data to the constituent models. For examinations of future climate scenarios, the accuracy of standard daily surface GCM output required to run the model is questionable (Mearns et al. 1984, Schneider 1984). The Climatological Prediction by Model Statistics (CPMS) technique is one method of producing more representative daily surface data from upper atmospheric GCM output, through a process similar to the National Weather Service Model Output Statistics (MOS) approach (Karl et al. 1990). A CPMSderived data set should allow projection of the green wave advance (as represented by the spring index) in a future GCM-generated climate scenario.

In addition, the development of appropriate fall phenological models gains new importance, as it would provide a measure of the onset of 'autumn', which would likely be representative of the timing of land surface-atmospheric changes in the fall-winter transition period. Unfortunately, attempts so far to identify an applicable fall phenological event have not been successful. Observers and coordinators of the lilac-honeysuckle phenological network have reported a weaker association in the fall between weather events and plant physiology. "Satellite observations may be one way of addressing this problem (Goward 1989).

Finally, it is important to note that the preliminary spring index proposed in this paper, while only directly applicable to a part of the plant community (certain shrubs), appears to be an indicator of general processes connected with plant-climate interaction. Further weather-phenology data collection, examination of

- M. T Vittum, Dept. of Horticultural Sciences, Cornell University, Geneva, NY 14456, USA pers. comms. March 1985 to July 1988; J. Prich, Huron Line Rd. Gagetown, MI 48735 , USA, pers. comms. April 1985 to August 1988 other phenological events, and incorporation of representative grasses, trees, and even agricultural crops might improve index performance. Ultimately, a better spring index might permit a parameterization of systematic changes in the land surface-atmosphere interface, associated with the onset of spring, useful for numerical model weather and climate predictions.

\section{LITERATURE CITED}

Andresen, J. A., Dale, R. F., Fletcher, J. J., Preckel, P. V. (1989). Prediction of county-level corn yields using an energy-crop growth index. Jr Climate 2: 48-56

Biswas, A. K. (1980). Crop-climate models: a review of the state of the art. In: Ausubel, J., Biswas, A. K. (eds.) Climatic constraints and human activities. Pergamon Press, Elmsford, New York, p. 75-92

Brinkmann, W. A. R. (1979). Growing season length as an indicator of climatic variations? Climatic Change 2: $127-138$

Brown, D.S. (1960). The relation of temperature to the growth of apricot flower buds. Proc. Am. Soc. Hort. Sci. 75: $138-147$

Caprio, J. M. (1974). The solar thermal unit concept in problems related to plant development and potential evapotranspiration. In: Lieth, H. (ed.) Phenology and seasonality modeling. Springer-Verlag, New York, p. 353-366

Coakley, S. M., McDaniel, L. R. (1988). Quantifying how climatic factors affect variation in plant disease severity: a general method using a new way to analyze meteorological data. Climatic Change 12: 57-75

Dube, P. A. Perry, L. P., Vittum, M. T (1984). Instructions for phenological observations: lilac and honeysuckle. Vermont Agr. Exp. Sta. Bull. 692. Univ. Vermont, Burlington, Vermont

Duchon, C. E. (1986). Corn yield prediction using climatology. Jr. Clim. Appl. Meteor. 25: 581-590

Goward, S. N. (1989). Satellite bioclimatology. Jr. Climate 2: $710-720$

Holloway, J. L., Jr, (1958). Smoothing and filtering of time series and space fields. Adv. Geophys. 4: 351-389

Hopkins, A. D. (1938). Bioclimatics - A science of life and climate relations. USDA Miscellaneous Publication \#280

Hopp, R. J. (1974). Plant phenology observation networks. In: Lieth, H. (ed.) Phenology and Seasonality Modeling. Springer, New York, p. 25-43

Hopp, R. J., Vittum, M. T (1977). Nature's own weather bureau. Organic Gardening and Farming 24 (April): $127-129$

Hopp, R. J., Vittum, M. T., Canfield, N. L. (1969). Instructions for phenological observations: Persian lilac. Northeast Regional Research Publication Pamphlet 36. Vermont Agriculture Experiment Station, University of VermontBurlington, Vermont

Isard, S. A., Easterling, W E. (1989). Predicting large-area corn yield with a weighted Palmer Z-Index. J. Climate 2: $248-252$

Karl, T R., Riebsame, W. E. (1989). The impact of decadal fluctuations in mean precipitation and temperature on runoff: a sensitivity study over the United States. Climatic Change 15: 423-447

Karl, I R. Wang, W., Schlesinger, M. E., Knight, R. W. Portman, D. (1990). A method of relating general circulation model simulated local climate to the observed local 
climate. Part I: Central tendencies and dispersion. J. Climate 3 (9): in press

Kaufmann, M. R. (1984). A canopy model (RM-CWU) for determining transpiration of subalpine forests. II. Consumptive water use in two watersheds. Can. J. For. Res. 14: $227-232$

Lettau, K. (1965). A new method for predicting the blooming date of spring flowers. Wis. Acad. Trans. 54 (A): 135-142

Lieth, H., Radford, J. S. (1971). Phenology, resource management, and synagraphic computer mapping. BioSci. 21 $62-70$

Mearns, L. O., Katz, R. W., Schneider, S. H. (1984). Extreme high-temperature events: changes in their probabilities with changes in mean temperature. J. Clim. Appl. Met. 23 1601-1613

Oke, T R. (1987). Boundary layer climates. Methuen, London

Partridge, N. L. (1947). A method for the estimation of the advancement of vegetation by the use of daily maximum temperatures. Proc. Am. Soc. Hort. Sci. 49: 7-14

Press, W. H., Flannery, B. P., Teukolsky, S. A., Vetterling, W. T. (1986). Numerical recipes: the art of scientific computing. Cambridge University Press, New York

Rind, D., Goldberg, R., Ruedy, R. (1989). Change in climate variability in the 21 st Century. Climatic Change 14:5-37

Rosenberg, N. J. (1974). Microclimate: the biological environment. John Wiley and Sons, New York

Rosenzweig, C. (1990). Crop response to climate change in the Southern Great Plains: a simulation study. Prof. Geographer 42: 20-37

Santer, B. (1985). The use of general circulation models in climate impact analysis - a preliminary study of the impacts of a $\mathrm{CO}_{2}$-induced climatic change on West European agriculture. Climatic Change 7: 71-93

Editor Professor V. Meentemeyer
Schneider, S. H. (1984). On the empirical verification of model-predicted $\mathrm{CO}_{2}$-induced climatic effects. In: Hansen. J. E., Takahashi, T. (eds.) Climatic processes and climate sensitivity. American Geophysical Union, Washington, D.C., p. $187-201$

Schwartz, M. D. (1985). The advance of phenological spring across Eastern and Central North America. Ph. D. dissertation, Department of Geography, University of Kansas, Lawrence

Schwartz, M. D., Karl, T R. (1990). Spring phenology: nature's experiment to detect the effect of 'Green-up' on surface maximum temperatures. Monthly Weather Review 118: 883-890

Schwartz, M. D., Marotz, G. A. (1986). An approach to examining regional atmosphere-plant interactions with phenological data. Jr. Biogeogr. 13: 551-560

Schwartz, M. D., Marotz, G. A. (1988). Synoptic events and spring phenology. Phys. Geogr. 9: 151-161

Segal, M., Garratt, J. R., Kallos, G., Pielke, R. A. (1989). The impact of wet soil and canopy temperatures on daytime boundary-layer growth. Jr. Atmos. Sci. 46: 3673-3684

Skaggs, R. H., Baker, D. G. (1985). Fluctuations in the length of the growing season in Minnesota. Climatic Change 7 : $403-414$

Smit, B., Brklacich, M., Stewart, R. B., McBride, R., Brown, M. Bond, D. (1989). Sensitivity of crop yields and land resource potential to climatic change in Ontario, Canada. Climatic Change 14: 153-174

Suckling, P. W. (1986). Fluctuations of last spring-freeze dates in the Southeastern United States. Phys. Geogr. 7: 239-245

Wilmott, C. (1982). Some comments on the evaluation of model performance. Bull. Am. Meteor. Soc. 63: $1309-1313$

Manuscript first received: April 9, 1990

Revised version accepted: June 22, 1990 